\title{
Relações público-privado na educação: políticas de democratização na concepção da educação popular?
}

\section{Public-private relations in education: democratization policies in the conception of popular education?}

Fernanda dos Santos Paulo ${ }^{1}$

\section{RESUMO}

Neste artigo, objetiva-se apresentar e caracterizar as relações público-privado, na perspectiva da Terceira Via, por meio de um estudo de caso: das experiências das Creches Comunitárias de Porto Alegre/RS e do Movimento de Educação Popular. Versamos acerca da dimensão da democratização da educação vinculada à concepção de Educação Popular e à luta pelo processo de formação de educadoras da Educação Infantil. A pesquisa é bibliográfica e documental. A partir da análise realizada e clareza conceitual sobre os processos de Terceira Via nas relações público-privadas, identificamos a minimização e o perecimento da democratização da sociedade, se associada à Educação Popular libertadora. 0 processo formativo de educadoras da Educação Infantil revela o empobrecimento e desvalorização da compreensão do Popular, indicando novas facetas de enraizamento da luta de classes.

\section{PALAVRAS-CHAVE}

Políticas educacionais. Educação Popular. Democracia. Educação Infantil. Terceira Via.

\footnotetext{
${ }^{1}$ Doutora e Mestra em Educação, Especialista em Educação Popular: Experiência na área de Educação, com ênfase em Educação Popular, atuando principalmente nos seguintes temas: Educação não Escolar; Educação Infantil, Educação de Jovens e Adultos, Universidade Popular, Pedagogia freiriana, Formação de Educadores Populares e Educadores Sociais, Movimentos Sociais, Políticas Públicas educacionais e história e memória da Educação Popular. E-mail: fernandaeja@yahoo.com.br
} 


\section{ABSTRACT}

In this article, the objective is to present and characterize public-private relations, from the perspective of the Third Way, through a case study: the experiences of Community Creches in Porto Alegre / RS and the Popular Education Movement. We are talking about the dimension of the democratization of education linked to the concept of Popular Education and the struggle for the process of training early childhood educators. The research is bibliographic and documentary. Based on the analysis carried out and the conceptual clarity on Third Way processes in public-private relations, we identified the minimization and perishing of the democratization of society, if associated with liberating Popular Education. The formative process of early childhood educators reveals the impoverishment and devaluation of the understanding of the Popular, indicating new facets for the rooting of the class struggle.

\section{KEYWORDS}

Educational policies. Popular Education. Democracy. Child education. Third Way. 


\section{INTRODUÇÃo}

Neste texto, caracterizaremos, de modo sucinto, as relações público-privado, na perspectiva da Terceira Via, por meio de um estudo de caso: das experiências das Creches Comunitárias de Porto Alegre/RS e do Movimento de Educação Popular. 0 foco refere à dimensão da democratização da educação vinculada à concepção de Educação Popular e à luta pelo processo de formação de educadoras da Educação Infantil. A pesquisa é de cunho bibliográfico e documental, caracterizando-se pela abordagem descritiva de caráter qualitativo. A partir dos resultados, foram elaboradas questões problematizadoras que servirão de pautas no processo formativo de educadoras vinculadas ao Grupo de Estudos e Pesquisa: Paulo Freire e Educação Popular, espaço de diálogos entre Movimento Social e universidade.

0 tema referente às relações entre o público e o privado é considerado novo para muitos estudantes da área da educação. Contudo, foi nos anos de 1990, no caso brasileiro, que as relações público-privado se estabeleceram como possibilidade de minimizar o Estado, colocando-se como alternativa ao modelo de execução de políticas sociais via Estado (público estatal) para um modelo de parceria público-privado. Alguns antecedentes são importantes para entendermos o contexto da proposta de Reforma do Aparelho do Estado, cujo responsável e intelectual defensor da Terceira Via é o professor Luís Carlos Bresser Pereira.

A Reforma Gerencial apresentada em 1995, através do Ministério da Administração Federal e Reforma do Estado - MARE, visava construir uma administração pública gerencial em nome da necessária substituição à administração burocrática. A Reforma do Estado emerge no governo do Presidente Fernando Henrique Cardoso, a qual influenciou os sistemas públicos de educação, mais especificamentena educação básica.

No entendimento de Bresser Pereira, o Terceiro Setor, via Organizações Sociais, contribuiria para diminuir a burocratização do Estado e democratizar a democracia, assim como na garantia da qualidade da educação, mediante serviços prestados por meio de parcerias entre Estado e Terceiro Setor.

A luta pela democratização da educação como direito social materializado em políticas públicas é antiga, sobretudo advinda de Movimentos Sociais e de intelectuais progressistas. É provocativa a compreensão da Terceira Via que considera a democracia relevante, e, portanto, deve ser reforçada e fortalecida.(GIDDENS, 2001; PERONI, 2008; 2012)

Concernente à educação, localizamos no Plano Diretor da Reforma do Aparelho de Estado:

\begin{abstract}
Deste modo, o Estado reduz seu papel de executor ou prestador direto de serviços, mantendo-se entretanto no papel de regulador e provedor ou promotor destes, principalmente dos serviços sociais como educação esaúde, que são essenciais para o desenvolvimento, na medida em que envolvem investimento em capital humano; para a democracia, na medida em que promovem cidadãos; e para uma distribuição de renda mais justa, que o mercado é incapaz de garantir, dada a oferta muito superior à demanda de mão-de-obra não-especializada. Como promotor desses serviços, o Estado continuará a subsidiá-los, buscando, ao mesmo tempo, o controle social direto e a participação da sociedade. (BRASIL: MARE, 1995, p.13. Grifos nossos)
\end{abstract}

Interessante que a expressão "capital humano" consta no documento, esta que se origina de uma concepção produtivista de educação, conforme Saviani (2007, p.367):

O pano de fundo dessa tendência está constituído pela teoria do capital humano, que, a partir da formulação inicial de Theodore Schultz, se difundiu entre os técnicos da economia, das finanças, do planejamento e da educação. E adquiriu força impositiva ao ser incorporada à legislação na forma dos princípios da racionalidade, eficiência e produtividade, com os corolários do "máximo resultado com o mínimo de dispêndio" e "não duplicação de meios para fins idênticos". (Grifos nossos)

Uma das obras que representa a Teoria do Capital Humano é a de Theodore Schultz, intitulada como Capital humano: investimentos em educação 
e pesquisa, produzida nos anos de 1970. A educação, nessa acepção, visa a formação de mão de obra qualificada para atuação no mercado de trabalho em expansão. Na pedagogia toyotista, ainda, enfatiza-se a importância da educação escolar, mas em uma perspectiva de formação de trabalhadores flexibilizados e competitivos. Daí as relações de currículo e escola baseados na Pedagogia das Competências e da promessa de empregabilidade, exigindo reformas com base nesse modelo produtivo toyotista, que secundariza o Estado. A pedagogia toyotista, também conhecida como "Pedagogia das competências", incide na desregulação das relações de trabalho, no pagamento e avaliação por desempenho, na meritocracia, na competitividade e em práticas de atividades empreendedoras. (KUENZER, 2005; SAVIANI, 2007). Para a pedagogia das competências, é preciso, segundo Lima (2012), um Estado mais competitivo, isto porque na pedagogia toyotista o Estado está em crise e precisa ser diminuído. Há duas possibilidades de reformar o Estado: o neoliberalismoe a terceira via. Essas teorias afirmam que a crise está no Estado, portanto as políticas sociais precisam ser redefinidas na execução, financiamento, direção e definição.

No Plano Diretor da Reforma do Aparelho de Estado, localizamos a referência ao terceiro setor e à democracia, diferentemente da lógica mercantil que ignora os processos democráticos. Vera Peroni (2003) revela que a Terceira Via, do mesmo modo que o neoliberalismo, alerta para a necessidade de reformar o Estado em virtude de uma histórica crise do Estado - negando a crise do modo de produção capitalista; contudo, segundo a autora, a justificativa resulta do contexto político, econômico e histórico advindos dos anos de 1990, sobretudo a partir da reestruturação do capitalismo.

Em nome da democracia, da participação e de uma política de descentralização criou-se o público não-estatal (Terceira Via), cooptando lideranças e movimentos comunitários como prestadores/executores de políticas sociais subsidiadas pelo Estado. A educaçãoé uma dessas políticas sociais, e torna-se um dos serviços a serem executados nos moldes da parceria público-privada, quer dizer, terceiro setor configurado pelo público não-estatal. Nesse caso, o Estado é o financiador, regulador e avaliador.

\section{EDUCAÇÃO POPULAR E MOVIMENTOS SOCIAIS}

O significado e o sentido da existência dos Movimentos Sociais e da Educação Popular é o de construir alternativas humanizadoras frente à dominação imposta pelo sistema capitalista perverso, o qual reproduz processos de exclusão e desigualdade social. A superação dessa lógica por um outro projeto de sociedade implica a compreensão da Educação Popular:

A concepção ético-política da Educação Popular, enquanto proposta de mobilização popular em prol das transformações sociais, se caracteriza, então, por estratégias bem claras e definidas de organização da sociedade civil através de várias formas de ações políticas que, ao respeitarem a cultura popular, visam, sobretudo, a conferir criticidade e organização política à mesma. Educação Popular é, então, a identidade de um movimento que parte da organização das classes populares em seus desafios concretos de cada realidade específica; não é, portanto, um nível nem uma modalidade de trabalho pedagógico interno ao sistema de ensino, mas a necessidade dos movimentos sociais estabelecerem sua prática pedagógica e se organizarem com idéias e estratégias de luta contra-hegemônica. (ZITKOSKI 2011, p. 15)

Nesse entendimento, Educação Popular e os Movimentos Sociais são espaços educativos e pedagógicos planejados com o objetivo de problematizar, contextualizar, lutar e oportunizar novas visões de mundo, as quais possam contribuir para a formação ético-política e cultural das pessoas. As diferentes modalidades de Educação Popular críticas e engajadas em um processo de humanização/libertação/emancipação humana são caminhos concretos de reconstrução da sociedade.

Os processos de descentralização nos Movimentos Sociais e da Educação Popular originam-se da trajetória desses espaços e concepções de 
cunho instituinte. Conforme Streck,et al, é preciso recuperar o significado e o sentido do "Popular":

O popular encontra, na educação forjada em movimentos de resistências dos povos tradicionais/originários, como os dos indígenas Guarani, localizados no Brasil e no Paraguai, e os zapatistas, no México; nas emancipações políticas e na constituição das jovens repúblicas latino-americanas, como Cuba (José Martí) e Venezuela (Simón Rodríguez); e, nas múltiplas experiências que atravessaram o século XX, perseguindo a justiça social, como na educação indígena, campesina e operária proposta por José Carlos Mariátegui, do Peru, - para citarmos alguns exemplos; aos dias de hoje, seus múltiplos espaços instituídos e instituintes, mas também seus múltiplos sentidos e significados. (2014, p. 30).

A expressão mais próxima ao referencial de educação crítica é movimentos de resistência. Esses movimentos tomam como princípio de luta a democracia, interpretando-a como movimento em prol da pedagogia da libertação; os princípios político-pedagógicos fundamentais de uma Educação Popular libertadora são: participação via trabalho coletivo, escuta e diálogo mediado por processos de reflexão crítica. 0 mais importante é a dialogicidade, porque é a matriz da democracia, desde que o trabalho coletivo considere as experiências vividas somadas à reflexão do conhecimento historicamente acumulado. As dimensões ética, estética e epistemológica compõem a concepção de Educação Popular libertadora. Isto é, somente via organização popular e de processos participativos dos movimentos sociais é possível promover abertura, experienciação e promoção da democracia. Freire (2006) nos diz que:

Uma coisa é falar bonito sobre democracia e outra é permitir que sua classe, em nome da democracia, se transforme numa desordem que inviabiliza a mínima produção de algo. [...]. E nós estamos ainda no processo de aprender como fazer democracia. E a luta por ela passa pela luta contra todo tipo de autoritarismo. (FREIRE, p. $122 ; 136)$
No mesmo livro, Paulo Freire recupera sua experiência como Secretário Municipal de Educação de São Paulo, pontuando que:

No momento, uma equipe intersecretarial - Se-
cretaria da Cultura, Secretaria da Educação, Se-
cretaria da Saúde, Secretaria da Habitação, Se-
cretaria do Bem-Estar Social, Secretaria dos Es-
portes - trabalha em relação direta com movi-
mentos sociais na elaboração de projetos de
educação popular. (2006, p. 32 . Grifos nossos).

Além disso, para o educador, tratando-se da Educação Popular democrática:

Significa lutar pela educação popular, pela par-
ticipação crescente das classes populares nos
conselhos de comunidade, de bairro, de escola.
Significa incentivar a mobilização e organização
não apenas de sua própria categoria, mas dos
trabalhadores em geral como condição funda-
mental da luta democrática com vistas à trans-
formação necessária e urgente da sociedade
brasileira. (FREIRE, 1996, p. 50).

Lima (2000)ressalta a importância dos princípios ético-políticos como uma prática social, incorporando uma dimensão crítica na educação democrática. Para Freire (2006), todo processo pedagógico e político é diretivo e intencional, e, por isso mesmo, requer a convicção de que toda educação implica um projeto de sociedade.

Nesse sentido, a luta pela transformação da sociedade de forma coerente com a Educação Popular exige a reinvenção da política, da educação, da cultura e da vida em sociedade. Ou seja, é imperativo o desafio de trabalharmos para um processo de ressignificação de nossas ações práticas no e com o mundo, de modo a ler e interpretar esse mundo com referências teórico-práticas, não nos deixando enganarmo-nos por projetos ardilosamente disfarçados de democracia, como é o caso das redefinições do papel do Estado, baseadas em Giddens (2001) e Bresser Pereira (1997).

Com base na concepção de Educação popular crítica, o projeto de Terceira Via e terceirosetor, apresentado na Reforma do Aparelho de Estado, 
possui grandes e impactantesimplicações para a democracia, poismuitos dos Movimentos Sociais, ao se transformarem em Organizações Sociais, modificaram as suas características e papéis em detrimento de suas redefinições: de mobilizadores e reivindicadores de políticas sociais, passaram a executores de políticas via parceria público-privada. Essas redefinições modificam as relações entre o público e o privado, re-significando a compreensão de democracia. A Terceira Via não abandona o conceito de democracia, o que pode nos seduzir em um primeiro momento, devido à sua criativa proposta de descentralização do poder através de parcerias entre o público (Estado) e o privado (Organizações Sociais). Consoante ao Freire (2006), no processo de construção da democracia, é de suma relevância o diálogo e participação dos Movimentos Sociais na elaboração de políticas sociais, o que é diferente de execução de políticas sociais. No Livro ÀSombra desta Mangueira, localizamos a discussão da defesa da política de direita no que tange à urgência de di-
Fundando-se, por exemplo, no dado real, concreto, o da discussão necessária hoje em torno do "tamanho" do Estado, advogam sua ausência quase total de áreas de fundamental interesse para a soberania do país. Daí a gulodice com que defendem a privatização de tudo que dê lucro. Daí a maneira agressiva, contundente com que atacam os que, mesmo defendendo uma nova compreensão das tarefas do Estado, e de seus limites, se insurgem contra a redução do Estado ao papel de defensor irredutível dos interesses dos ricos. (FREIRE, 2015, p. 440).

Paulo $(2010 ; 2013)$ alerta para políticas que, em nome da democracia, simulam projetos e propostas de educação popular que, na verdade, são antimobilizadoras, compreendendo o popular como popularização a qualquer custo, mantendo o modo de produção capitalista. Como exemplo da reconfiguração do Estado, via Terceira Via, apresentamos uma das experiências de Porto Alegre, Rio Grande do Sul.

\section{Formação de educadoras das escolas comunitárias: relações público-privado}

Quanto ao processo de formação de educadoras das Escolas Comunitárias de Educação Infantil, em regime de parcerias público-privadas, situadas em Porto Alegre, Rio Grande do Sul, Flores (2007), Susin $(2005$;2009) e Paulo $(2010 ; 2013)$ apresentam pesquisas que identificam historicamente $o$ processo de construção do regime de parcerias público-privado da política de Educação Infantil na capital gaúcha. Recentemente, em continuidade destes estudos, contamos com a dissertação de Prunier (2018), que versa acerca das parcerias público-privado e suas implicações para o trabalho docente.

No caso de Porto Alegre, contexto deste estudo, foi no ano de 1993 que se deu o início das primeiras parcerias entre Prefeitura Municipal de Porto Alegre, via Secretaria Municipal de Educação e as Organizações Sociais, mediante assinatura de convênio para a institucionalidade das Creches Comunitárias. Nesse período, foram aproximadamente quarenta instituições que firmaram parceria com a administração pública municipal. 0 processo de parceria realizou-se mediante intensa mobilização de movimentos comunitários, em especial das periferias da cidade, sobretudo em virtude de dois fenômenos, a saber: 1) Extinção da Legião Brasileira de Assistência; 2) Contexto do Estatuto da Criança e do Adolescente de 1990. (PAULO, 2010; 2013)

Inicialmente, as educadoras das Escolas Comunitárias de Educação Infantil não possuíam formação profissional específica. Atualmente, estudos de Paulo (2013) e Prunier (2018), somados aos dados coletados na Associação de Educadores Populares de Porto Alegre (AEPPA), revelam que o contexto de profissionalização dessas educadoras permanece precarizado, divergindo das legislações ${ }^{1}$ da educação nacional, as quais exigem licenciatura para atuação docente na educação básica.

1 Referente à exigência de formação profissional, conferir as seguintes legislações: Lei de Diretrizes e Bases da Educação Nacional (no 9394/1996: Art. 62) e o atual Plano Nacional de Educação de 2014, na meta 15. 
Diante disso, apontaremos as implicações dessas parcerias público-privado no processo de formação das educadoras das Escolas de Educação Infantil de Porto Alegre - RS. Nosso estudo é bibliográfico e documental, utilizando-nos de materiais disponibilizados pela AEPPA.

A parceria público-privado na Educação Infantil Comunitária de Porto Alegre, por meio das Instituições de Educação Infantil sem fins lucrativos, possui implicações com relação ao processo de precarização na/da formação de profissionais da Educação Básica, tais como: o retorno das políticas assistencialistas de cunho benevolente e da desestatização por parcerias público-privado por meio da transferência da execução de políticas educacionais que deveriam ser de responsabilidade do munícipio (BRASIL, 1996) para as Organizações Sociais. Essa transferência de responsabilidade, embora parcial, representa uma das faces do debate do neoliberalismo que versa sobre a necessidade de diminuir o Estado via privatização; similarmente, a discussão da Terceira Via que, de igual modo, afirma que o Estado deve diminuir, considera imperativa a democratização na execução de políticas sociais, transferindo-as para a Sociedade Civil Organizada (PERONI, 2008; 2012). Nesse contexto, nos interessa analisar o trabalho das profissionais de educação que atuam nessas instituições, mais especificamente, a formação profissional delas.

Essas educadoras da Educação Infantil Comunitária de Porto Alegre, na sua maioria, residem próximo ao espaço de atuação profissional, foram indicadas ao emprego e não possuem formação em nível superior. Segundo estudos realizados na AEPPA em 2019, a grande parte das educadoras não possui mais vínculos com os movimentos populares das comunidades, como aquelas que iniciaram como educadoras entre os anos de 1990 a 2006. Essa constatação revela o distanciamento das relações dos movimentos sociais, cuja pauta inicial foi a luta pelo direito à creche, com a atual política de parcerias público-privado.

Inicialmente, o processo de conveniamento foi influenciado pelos movimentos populares comunitários através da luta por política pública da Educação Infantil, permanecendo executado com a participação de lideranças comunitárias, sobretudo no tocante à gestão das escolas comunitárias. Esses gestores, na sua maioria, não possuem formação acadêmica.

As Instituições de Educação Infantil sem fins lucrativos, conveniadas com a Secretaria Municipal de Educação (SMED) de Porto Alegre, não possuem trajetória de debate sobre o trabalho e formação docente das profissionais de educação. Flores (2007), Paulo (2013) e Susin (2005; 2009) sinalizam essa problemática apontando que o único movimento em defesa da formação das educadoras atuantes nas Instituições de Educação Infantil Comunitárias é a AEPPA. Alusivo a esse contexto, os trabalhos que discorrem sobre a temática da formação de educadoras constam no Quadro 1:

Quadro 1 - Teses e Dissertações sobre o contexto da Educação Infantil Comunitária.

\begin{tabular}{|l|l|}
\hline OtiliaKroeffSusin (2005) & $\begin{array}{l}\text { A educação infantil em Porto Alegre: um estudo das creches } \\
\text { comunitárias }\end{array}$ \\
\hline Maria Luiza Rodrigues Flores (2007) & $\begin{array}{l}\text { Movimento e complexidade na garantia do direito à Educação } \\
\text { Infantil: um estudo sobre políticas públicas em Porto Alegre } \\
(1989-2004)\end{array}$ \\
\hline Maria OtiliaKroeffSusin (2009) & $\begin{array}{l}\text { A qualidade na educação infantil comunitária em Porto Alegre: } \\
\text { estudo de caso em quatro creches conveniadas }\end{array}$ \\
\hline Fernanda dos Santos Paulo (2013) & $\begin{array}{l}\text { A formação dos (as) educadores (as) populares a partir da } \\
\text { práxis: um estudo de caso da AEPPA }\end{array}$ \\
\hline Simone Souza Prunier (2018) & $\begin{array}{l}\text { A parceria público-privada na educação infantil em Porto } \\
\text { Alegre: } \text { suas implicações para o trabalho docente. }\end{array}$ \\
\hline
\end{tabular}

Fonte: da Autora 
As Teses e dissertações discutem a trajetória histórica e política das parcerias público-privado da Educação Infantil em Porto Alegre, referenciando a situação do negligenciamento da formação das trabalhadoras da primeira etapa da Educação Básica.

0 trabalho das profissionais de Educação Infantil que atuam em instituições parceiras é configurado por regime de trabalho celetista, cuja denominação do cargo é de auxiliar de desenvolvimento infantil ou técnica do desenvolvimento infantil. Essas nomenclaturas constam na tabela de Função do Sindicato dos Empregados em Entidades Culturais, Recreativas, de Assistência Social, de Orientação e Formação Profissional no Estado do Rio Grande do Sul (SENALBA/RS), que representa essas profissionais. Como foi mencionado anteriormente, a maioria não possui formação em nível superior, e as graduadas são contratadas como técnicas do desenvolvimento infantil. Ou seja, não há nenhuma trabalhadora da Educação Infantil das instituições parceiras com o poder público contratada como professora. Essa situação é denunciada pela AEPPA como condição precarizada de trabalho e desfavorável para a comunidade, já que as crianças não têm garantia de uma Educação Infantil com a mesma qualidade que a ofertada pela rede municipal.

A relação público-privado tem demonstrado impactos no trabalho dessas educadoras, que atuam como docentes, mas não são valorizadas como tal. Contraditoriamente, as legislações municipais amparam esse tipo de contratação, divergindo das legislações educacionais em âmbito nacional, como podemos conferir a seguir:

Art. 240 professor é o responsável pelo processo educativo nas escolas/instituições e deverá estar presente nos grupos etários, nos turnos de atendimento.

$\S 1^{\circ}$ Será admitida a atuação de profissionais de apoio ao professor, exigida a formação mínima de ensino médio, acrescido de capacitação específica a ser regulamentada por norma própria.

$\S 2^{\circ}$ As ações dos profissionais de apoio devem sedarsempresobaorientaçãoeresponsabilidade do professor. (Grifo da autora)
A legislação acima é proveniente do Conselho Municipal de Educação (CME) de Porto Alegre, que regulamentou a Resolução de no 015/2015. Constatamos que a terminologia "professor" consta no documento, mas na realidade concreta não há nenhum trabalhador contratado com esse cargo. Outrossim, algumas educadoras possuem a titulação de docente e são contratadas como profissional habilitada para o magistério com o cargo de Técnica de Desenvolvimento Infantil. Atualmente, há uma promessa de contratação de professores em contrapartida a um aumento de repasse às escolas comunitárias, estimado em $81 \%$ até 2020 , conforme notícia na página da SMED2

Relato de uma educadora, participante da AEPPA, confirma a ligação entre o repasse financeiro e a formação docente: "Acredito que com o aumento de verba venha junto a exigência semelhante às escolas municipais, por isso está tudo no mesmo pacote de educação infantil. Ele [secretário de educação] deixou bem claro que junto vem a contrapartida que é contratação de professores para todas as faixas etárias". Esse depoimento indica a compreensão de formação docente como favor e bônus, ao invés de direito das crianças em ter profissionais qualificados.

A princípio, a política de conveniamento era para ser provisória, conforme conversa realizada com José Clóvis de Azevedo, em decorrência de estudos e pesquisas realizadas a partir da AEPPA. Confirma-se essa intenção de provisoriedade na tese de Flores (2007). Nessa mesma pesquisa, concernente ao contexto de parceria e à questão do processo formativo das educadoras, podemos identificar que:

O convênio entre o município e as creches vinculadas à extinta LBA incluía um repasse mensal de verbas por parte da prefeitura a cada instituição conveniada, proporcional ao número de crianças atendidas, para fins de manutenção e pagamento de pessoal. Além do repasse, as instituições passaram a receber

2 Disponível em: http://www2.portoalegre.rs.gov.br/smed/. Acesso: 13 nov. 2019. 
assessoria pedagógica e de prestação de contas da SMED, além de vagas em cursos, seminários, encontros de formação locais e regionalizados e, a partir de 2001, também vagas em cursos de formação inicial em serviço. Esse convênio, que inicialmente incluiu 40 creches, foi uma tentativa mediadora, já que o interesse das creches era de que o município as assumisse integralmente. (FLORES, 2007, p. 102103, grifo nosso).

A citação acima denota um contexto de redefinição das políticas educacionais na esfera municipal,redefinindo o papel do Estado como principal garantidor dos direitos educacionais. Hoje, podemos afirmar que a ampliação das parcerias público-privado é parte da materialização do Plano Diretor de Reforma do Aparelho do Estado, do governo de Fernando Henrique Cardoso. A relação público-privado, segundo Peroni (2012), tem como lógica tomar a sociedade civil como parceira e empreendedora, isto é, corresponsável pelas políticas educativas, via execução das mesmas.

Nesse período particular do capitalismo, e no caso específico de Porto Alegre, é importante ressaltar que as mudanças descritas não são conjunturais. Vimos que tem sido questões estruturais, pois não houve a ampliação da rede municipal de escolas de Educação Infantil, expandindo, assim, a política de Educação Infantil no formato de parceria (Terceira Via). Outra evidência foi no tocante à formação, pois não tem tido a exigência de graduação para as educadoras da rede parceirizada e nas formas de contratação.

Após o Marco Regulatório das Organizações da Sociedade Civil (Lei 13.019/2014) há uma cobrança de formação específica para as educadoras da rede parceirizada, estando em conformidade com a Lei de Diretrizes e Bases da Educação Nacional (LDBEN, 1996) em seu artigo 62. O Marco Regulatório, constituído em âmbito nacional, se propõe a conferir transparência para a atuação das organizações da sociedade civil em parceria com a administração pública, em especial quando há repasse financeiro - caso da Educação Infantil de Porto Alegre. O Marco Regulatório é, portanto, a materialização das redefinições do papel do Estado na perspectiva da Terceira Via - regulando as parcerias público-privado.

A SMED de Porto Alegre tem anunciado a necessidade da formação das educadoras da Educação Infantil atuantes no contexto da rede parceirizada, registrando nos Editais de Chamamento Público das Organizações da Sociedade Civil; todavia, não exige a contratação de professor enquanto cargo profissional. Importa ressaltar que essas instituições são consideradas como prestadoras de serviços educacionais existentes há mais de 25 anos $^{3 "}$. Na definição de prestação de serviços, observa-se a desresponsabilização do poder público nas formas de contratação das educadoras e na exigência de formação docente, visto que o Estado, nesse contexto, tem o papel de financiador e avaliador.

Um dos anexos localizados nas orientações pedagógicas dos Editais de Chamamento Público, destinado às parcerias público-privado, relativo à formação de educadoras, não requisita profissional habilitado para o magistério no caso da Creche (Berçário ao maternal), sendo, portanto, contratados como Profissional de Apoio. 0 curso denominado Capacitação para Profissionais de Apoio da Educação Infantil é um requisito obrigatório para o cargo em questão. No entanto, admite-se a permanência de educadores assistentes, desde que cursando o Ensino Médio ${ }^{4}$. Os cursos para atuação na Educação Infantil são realizados em instituições particulares, com uma carga-horária de no mínimo 160 horas.

\section{CONSIDERAÇÕES FINAIS}

A reconfiguração do Estado via reforma Estatal não só reestruturou o seu papel como modificou a compreensão de democracia. A democracia na

\footnotetext{
3 Diário Oficial de Porto Alegre - Órgão de divulgação do Município - Ano XXIV - Edição 6124 - Terça-feira, 12 de novembro de 2019. Disponível em: http://dopaonlineupload.procempa.com.br/ dopaonlineupload/3095_ce_20191112_executivo.pdf Acesso em: 13 de nov. de 2019.

4 Disponível em: http://lproweb.procempa.com.br/pmpa/ prefpoa/smed/usu_doc/anexo_iii_-_orientacoes_pedagogicas_nova_versao.pdf. Acesso em: 13 de nov. 2019.
} 
Terceira Via significa responsabilizar, em nome da descentralização, da participação e da crise do Estado, as comunidades, as periferias, as classes populares. A Educação Popular na perspectiva da pedagogia crítica não se aproxima da Terceira Via, distancia-se em pelo menos dois pontos: 1) a Educação Popular tem um projeto revolucionário de educação e sociedade; 2) Um dos instrumentos de luta da Educação Popular, de reivindicação e de resistência às desigualdades sociais é o Movimento Social; Ambos perderam suas principais características quando passaram a ser aparelhosprestadores de serviços para o Estado, deixando de existir como espaços destinados às lutas históricas das classes populares.

Constatamos que no caso específico de Porto Alegre, referindo-se às relações público-privado, no contexto da política da Educação Infantil, as transformações são resultantes da reconfiguração das estratégias do neoliberalismo por meio da Terceira Via.

No tocante à formação, observamos que a des- cula à precarização do trabalho e ao retorno das políticas assistencialistas de caráter beneficente. Nesse viés, a exigência de formação docente e de valorização da mesma, torna-se desnecessária, podendo, inclusive, o trabalho assumir característica de voluntariado.

As relações Estado e Sociedade Civil Organizada, no caso estudado, configuram-se mediante contratos de contrapartidas, característica da concepção das políticas sintonizadas com a Terceira Via, a qual preconiza a participação e responsabilização dos sujeitos. Ao anunciar o aumento de repasse financeiro às Instituições de Educação Infantil parceirizadas, a SMED coloca como contrapartida a exigência de contratação de professores, como se fosse natural existir escolas sem docentes. 0 direito à educação como bem público de qualidade social, referenciada pela Educação Popular, inexiste sem democracia, assim como diverge da educação na lógica da competição, da desvalorização do trabalho docente, do individualismo, da meritocracia, do egoísmo e do privado. 


\section{REFERÊNCIAS}

BRASIL. Estatuto da Criança e do Adolescente. Lei n. ㅇ 8.069, de 13 de julho de 1990.

BRASIL, Ministério da Administração e Reforma do Estado (MARE). Plano Diretor da Reforma do Aparelho de Estado. Brasília, 1995.

BRASIL. Lei de Diretrizes e Bases da Educação Nacional. Lei n. o 9.394, de 20 de dezembro de 1996.

BRASIL, Plano Nacional de Educação. Lei 13005, 25 de junho de 2014

BRASIL. Lei n.13.204, de 14 de dezembro de 2015. Estabelece o regime jurídico das parcerias entre a administração pública e as organizações da sociedade civil(...)Brasília: Presidência da República, 2015.

FREIRE, P. A educação na cidade. 7.ed. São Paulo: Cortez, 2006.

FREIRE, P. À sombra desta mangueira. 11. ed. - Rio de Janeiro: Paz e Terra, 2015.

FLORES, M. L. R. Movimento e Complexidade na garantia do direito à Educação Infantil: um estudo sobre políticas públicas em Porto Alegre. Universidade Federal do Rio Grande do Sul. 2007. 289 f. Tese (Doutorado em Educação) - Programa de Pós-Graduação em Educação.

GIDDENS, Anthony. A Terceira Via: reflexões sobre o impasse político atual e o futuro da social-democracia. Rio de Janeiro: Record, 2001.

HARVEY, D. O Neoliberalismo: história e implicações. São Paulo: Loyola, 2008.

LIMA, Licínio. Organização escolar e democracia radical: Paulo Freire e a governação democrática da escola pública. São Paulo: Cortez Editora, 2000;

KUENZER, A.Z. Exclusão includente e inclusão excludente: a nova forma de dualidade estrutural que objetiva as novas relações entre educação e trabalho. In: Saviani, D.; Sanfelice, J.L.; Lombardi, J.C. (Org.). Capitalismo, trabalho e educação. 3. ed. Campinas: Autores Associados, 2005. p. 75-96.

PAULO, F.S. Formação dos/as educadores/as populares de Porto Alegre formados/as em Pedagogia: identidade, trajetória e desafios. 2010. 79f. Trabalho de Conclusão de Curso (Especialização em Educação Popular) - Instituto Superior de Educação Ivoti \& Instituto de Desenvolvimento Brava Gente, Porto Alegre.

PAULO, F.S. A Formação dos (as) educadores (as) populares a partir da Práxis: Um estudo de caso da AEPPA. 2013. 278 f. Dissertação (Mestrado) -Programa de Pós-Graduação em Educação. Universidade Federal do Rio Grande do Sul, Porto Alegre. PEREIRA, L. C. B. A Reforma do estado dos anos 90: lógica e mecanismos de controle.Brasília: Ministério da Administração
Federal e Reforma do Estado, 1997. (Cadernos MARE da reforma do estado; v. 1).

PERONI, Vera. Política educacional e papel do Estado no Brasil dos anos 90.São Paulo: Xamã, 2003.

PERONI, V. M. V. Políticas Públicas e gestão da educação em tempos de redefinição do papel do Estado. Texto apresentado na Anped Sul, 2008 (CD) artigo disponível em: http:// www.ufrgs.br/faced/peroni; Acesso em 13 fev. 2017.

PERONI, V. M. V. A gestão democrática da educação em tempos de parceria entre o público e o privado. Pro-Posições, Campinas, v. 23, n. 2 (68), p. 19-31, maio/ago. 2012.

PRUNIER, S. S. A parceria público-privada na educação infantil em Porto Alegre: suas implicações para o trabalho docente. Porto Alegre, 2018. 192 f. Dissertação (Mestrado em Educação) - Programa de Pós-Graduação em Educação, Faculdade de Educação, Universidade Federal do Rio Grande do Sul. 2018.

PORTO ALEGRE.Fixa normas para oferta da Educação infantil no Sistema Municipal de Ensino de Porto Alegre. Resolução n. ${ }^{\circ}$ 003 de 25 de janeiro.Disponível em: http://lproweb.procempa.com.br/PMPOA/prefpoa/smed/usu_doc/res00301.pdf. Acesso em: 04 jan. 2017.

PORTO ALEGRE.Fixa normas para oferta da Educação infantil no Sistema Municipal de Ensino de Porto Alegre. Resolução n. ${ }^{0}$ 015 de 18 de dezembro de 2015.Disponível em: http://lproweb.procempa.com.br/pmpa/prefpoa/smed/usu_doc/refantil.pdf. Acesso em: 05 jan. 2017.

SUSIN, M. O. K. A Educação Infantil em Porto Alegre: Um estudo das creches comunitárias. Porto Alegre: Universidade Federal do Rio Grande do Sul. 2005. 248 p. Dissertação (Mestrado em Educação) - Programa de Pós-Graduação em Educação.

SUSIN, M. O. K. A Qualidade na Educação Infantil Comunitária de Porto Alegre: estudo de caso em quatro creches conveniadas. Porto Alegre: Universidade Federal do Rio Grande do Sul. 2009. 306 f. Tese (Doutorado em Educação) - Programa de Pós-Graduação em Educação.

STRECK, D. R.; PITANO, S. d. C.; MORETTI; C. M.; SANTOS. K.; LEMES. M.; PAULO, F. d. S. Educação popular e docência - 1. ed. - São Paulo: Cortez, 2014. -(Coleção docência em formação: saberes pedagógicos)

SAVIANI, D.; SANFELICE, J. L. (Org.). Capitalismo, trabalho e educação. Campinas: Autores Associados, 2002.

SAVIANI, D. História das ideias pedagógicas no Brasil. Campinas: Autores Associados, 2007.

ZITKOSKI, Jaime José. Educação Popular na América Latinaraízes históricas e temas emergentes: uma leitura a partir de Freire. In: Redes de pesquisa: Trabalho, movimentos sociais e educação / Ribeiro, Marlene Ribeiro (Orgs.).Porto Alegre: Itapuy, 2011. 